\title{
Brasília na rede das cidades globais: apontando uma tendência*
}

Brasilmar Ferreira Nunes**

Resumo: $\mathrm{O}$ artigo discute o potencial de Brasília se inserir na rede mundial de cidades, considerando sua peculiar dinâmica socioeconômica. Consolida-se aqui, 54 anos após sua inauguração, uma cidade que vive constantes processos de mudança, mas que ainda se acha atrelada ao setor público, esfera que lhe dá sua identidade. A assimetria que se observa entre, de um lado, uma cidade racional que se rebate num desenho modernista e, de outro, uma cidade que cresce nas suas periferias de forma anárquica, reproduzindo modelos das demais cidades brasileiras, evidenciam uma estrutura social com enormes graus de desigualdade e de diferenciação. A dinâmica populacional do Distrito Federal e entorno ultrapassa cada vez mais as determinações e os estímulos oriundos do setor público, concentrados no seu Plano Piloto. Ao contextualizá-la na lógica contemporânea das cidades "globais", na tentativa de diversificar a fonte de investimentos, Brasília procura oferecer vantagens comparativas frente a outras metrópoles que com ela concorrem. Nesse sentido, o artigo defende que a capital vive hoje uma etapa original na sua evolução, mesmo se a incompatibilidade aparente entre sua função política, que de certa forma restringe suas potencialidades, e as forças de mercado, a levam a modificar sua natureza original.

Palavras-chave: Brasília; burocracia; cidades globais; desigualdades sociais; planejamento urbano.

\section{Antecedentes}

$\mathrm{N}$ este paper, buscaremos demonstrar que nesses 54 anos que se passaram desde a inauguração da nova capital, a cidade de Brasília vem se consolidando como uma das principais metrópoles brasileiras. A hipótese é que a dinâmica demográfica/econômica que nela se instala, permeada pela hegemonia do setor público presente na cidade, leva a supor que Brasília tem potencial para, rapidamente, inserir-se, tal como ocorreu em escala nacional, na rede mais ampla de cidades em âmbito global.

Brasília ${ }^{1}$ originalmente foi pensada e construída para desempenhar as funções de capital política do Brasil, como parte de uma estratégia de governo de interiorizar a dinâmica econômica do país, necessidade essa advinda das funções político-administrativas da cidade, as quais induziriam investimentos de diferentes ordens e terminariam por integrar uma vasta região até então fora do eixo principal da economia brasileira. Historicamente, a mudança da capital do Brasil para "Brasília" começa a tomar corpo em 1891 quando essa intenção é incorporada à Constituição brasileira. Na sequência, para cumprir com a determinação constitucional sobre a transferência da capital para

\author{
* O autor agradece \\ a Osvaldo de Assis, \\ doutorando do \\ Centro de Pesquisa \\ e Pós-Graduação \\ sobre as Américas \\ (Ceppac) da UnB \\ pela leitura e \\ comentários e ainda \\ pela preparação das \\ tabelas e gráficos \\ que compõem o \\ texto. \\ ** Professor \\ do PPGSOL. \\ Pesquisador do \\ CNPq. \\ <unbnunes@gmail. \\ com> \\ 1. O nome Brasília \\ foi sugerido para \\ a futura capital \\ em 1823 por José \\ Bonifácio.
}


2. Em clássico argumento na sociologia brasileira, Sérgio Buarque, em Raízes do Brasil sustenta que a cidade portuguesa aparece na metáfora como nascendo espontaneamente (semeando, brota naturalmente), enquanto as cidades coloniais espanholas eram fruto de planejamento e de um laborioso trabalho empreendido pelos pioneiros (metáfora do ladrilho, algo trabalhado, pensado e planejado). 0 argumento de Holanda é hoje sujeito a críticas, sobretudo porque inúmeras cidades do Brasil colonial/ português não nascem espontaneamente, ao contrário, foram desenhadas e implantadas a partir da prancheta. O exemplo mais recorrente é o de Salvador na Bahia, primeira capital da colônia brasileira. Da mesma forma, nem todas as cidades da América Espanhola foram desenhadas na prancheta. Vale a pena refletir sobre as diferentes maneiras de se fundar cidades na América colonial.

\section{Esse}

embaralhamento do espaço construído em nossas cidades, onde áreas carentes e áreas privilegiadas aparecem muito próximas, vai sendo aos poucos filtrada e cada vez mais há uma separação evidente entre os dois o interior, o governo federal cria, no ano 1892, a Comissão Exploradora do Planalto Central do Brasil para demarcar a localização geográfica da nova capital a ser construída. Tal comissão ficaria conhecida como Missão Cruls.

No entanto, a transferência da capital para o interior apenas se concretiza na segunda metade dos anos 1950 e muito em virtude de uma elevada dose de arrojo do então presidente Juscelino Kubitschek (1956-1961), quando se compromete com essa determinação constitucional e decide executar um projeto de tamanha envergadura. Com o recuo do tempo, podemos hoje avaliar a aventura que foi a empreitada de transferência da capital do litoral para o centro do país. Aventura tanto mais evidente se considerarmos o arrojo dos pressupostos modernistas do projeto da nova capital que rompia com a tradição das cidades brasileiras, a maioria delas constituídas com base no modelo urbanístico português. A cidade colonial portuguesa era marcada como por espaços flexíveis e pragmáticos, sem o critério segregacionista que poderá ser mais claramente observado nas cidades que as sucedem. Ao contrapor o modelo espanhol de cidades nas Américas ao modelo português, Risério (2012: 96) observa que

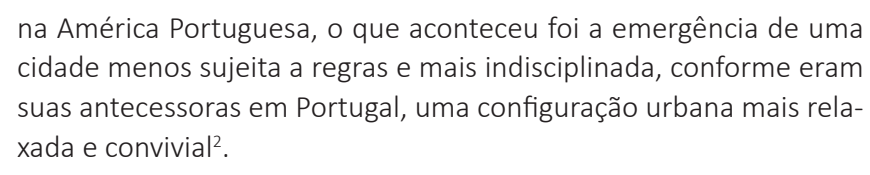

As cidades do Brasil colonial, apesar do regime escravocrata, além da enorme desigualdade social característica daquela sociedade, não apresentavam uma acentuada especialização do espaço urbano com divisões sociais explícitas. A estrutura social e econômica se rebatia no espaço urbano de forma ambígua, e vão se consolidando, em diversas cidades brasileiras, a presença de favelas, cortiços ou mocambos em áreas contíguas a espaços de moradia das classes mais favorecidas ${ }^{3}$.

No século XX, o projeto urbanístico do Plano Piloto de Brasília quebra essa tradição de espaço urbano brasileiro, pois a cidade para a nova capital é pensada para uma única categoria socioprofissional, qual seja, o funcionalismo público ${ }^{4}$. O projeto que vence o concurso buscou contemplar exatamente tais funções e assim atender às exigências do edital do concurso de projetos para a nova capital onde se instalariam os órgãos da administração federal e se definiriam os padrões habitacionais para a burocracia que iria "tocar" a máquina administrativa federal. Uma cidade administrativa não apenas para sediar as instituições estatais, como ainda abrigar os servidores públicos do governo federal.

O sítio escolhido para o futuro Distrito Federal apresentava baixíssima densidade demográfica. Era uma área ainda de predomínio rural ${ }^{5}$, o que permitiu aos autores do 
projeto formular uma proposta radical de cidade, resultando no exemplo mais completo das proposições de espaço urbano contidos na "Carta de Atenas", relatório do Congresso Internacional de Arquitetura Moderna (Ciam), de 1933, na qual está delineado o que deveria ser o urbanismo em uma cidade moderna. Em razão de os vencedores do concurso estarem vinculados internacionalmente aos urbanistas que apoiavam a concepção de cidade contida naquele relatório, as críticas à Carta de Atenas por arquitetos da Europa e dos Estados Unidos, não foram absorvidas pelos arquitetos do grupo carioca que formulou o projeto vencedor ${ }^{6}$.

\section{Gênese dos grupos econômicos de interesse na nova capital}

A partir de sua inauguração, três forças vão compor o leque de interesses que se reproduz ao longo do tempo no espaço urbano de Brasília e irão influenciar o padrão de ocupação de seu território. O setor público injeta recursos para efetivar o projeto mudancista; o capital imobiliário assume o papel de empreendedor e principal empregador privado; e, por fim, a terceira força será formada pela mão de obra assalariada, sobretudo por trabalhadores da construção civil. Essas são as principais, muito embora tenha surgido, ainda que de modo incipiente, um comércio de bens o qual garantia o cotidiano dos trabalhadores sem no entanto demonstrar força suficiente para influenciar os rumos da nova capital. O volume de recursos aplicados nas construções dos edifícios públicos transforma um território vazio em outro com forte poder de atração de trabalhadores braçais da construção civil.

Há, portanto, em seus primórdios, duas faces do processo de consolidação da cidade: a chegada permanente de migrantes originários sobretudo de regiões deprimidas do país e, em segundo lugar, o funcionalismo público, o capital imobiliário, o setor comercial e os serviços que irão constituir o leque dos interesses econômicos estabelecidos, os quais definirão o jogo político e a expansão urbana de Brasília. Ao longo desse meio século, tais segmentos se consolidaram, se fortaleceram e se diversificaram cada vez mais em um espaço urbano com forte dinamismo, como também polarizaram o jogo social e político local.

A cidade passou a ser marcada pela forte presença dos "serviços" na formação da riqueza local. Sua participação na formação do PIB sempre esteve na casa dos 90\%. 0 destaque neste segmento é a administração pública que, anos 1990, já representava $40 \%$ da economia e nos anos 2000 chegou a 54\%7.

Um olhar mais atento nos números do PIB brasiliense - em comparação com o das demais cidades do país - permite constatar que, a despeito da forte participação do setor público, o Distrito Federal tem se destacado nos demais segmentos da mundos. Sempre há as exceções que justificam o fenômeno, mas sobretudo com a generalização dos condomínios horizontais

a separação que segrega drasticamente o espaço das cidades por faixa de renda está alterando a lógica urbana tradicional do Brasil.

4. Exemplos de cidades construídas com o objetivo de serem capitais não nos eram desconhecidos. Internamente, já tínhamos, entre outras, a experiência de Belo Horizonte (MG), em 1897,e de Goiânia (GO), em 1935, capitais estaduais planejadas.

5. No período que antecede a construção da cidade, havia na área escolhida para o futuro Distrito Federal dois núcleos urbanos, Planaltina e Brazlândia, somando cerca de nove mil habitantes, o que corresponde a uma densidade de 1,5 $\mathrm{hab} / \mathrm{km}^{2}$.

6. As lutas características no campo da arquitetura e do urbanismo vão ter no Brasil e em Brasília um elemento favorável definindo grupos hegemônicos e padrão estético explicitando assim os agentes hegemônicos do campo. Cf. Nunes 
(2004), Durand (1991) e Marques (1995).

7. O patamar de $54 \%$ do PIB proveniente do setor público, que contribuiu para conferir à cidade o primeiro lugar neste indicador para o setor de serviços, em números absolutos, está bem acima da média nacional, que é de $16 \%$ para este segmento no ano de 2010. economia, principalmente quando se observa o volume de produção em números absolutos. Apesar de responder por apenas 0,3\% do PIB do Distrito Federal, o setor agrícola, por exemplo, é o 160 maior do Brasil, com destaque para a produção de milho e soja. O setor industrial também desponta como um dos mais importantes do país. Mesmo representando aproximadamente 6,5\% do PIB local, Brasília é a 10a zona industrial mais importante das cidades brasileiras, contribuindo com quase $1 \%$ de toda a produção nacional, destacando-se as indústrias voltadas para a construção civil e de transformação (Tabela 1).

TABELA 1

PIB, SEGUNDO AS ATIVIDADES ECONÔMICAS

DISTRITO FEDERAL - 2002/2010 (R\$ MILHÃO)

\begin{tabular}{|c|c|c|c|c|c|c|}
\hline \multirow{2}{*}{ Setores e atividade econômica } & \multicolumn{2}{|c|}{2002} & \multicolumn{2}{|c|}{2010} & \multirow{2}{*}{$\begin{array}{c}\text { variação } \\
\text { 2002/2010 }\end{array}$} & \multirow{2}{*}{$\begin{array}{l}\text { Ranking } \\
\text { nacional }\end{array}$} \\
\hline & $\mathrm{R} \$$ & $\%$ & $\mathrm{R} \$$ & $\%$ & & \\
\hline Agropecuária & 240 & 0,5 & 335 & 0,3 & 39,6 & 16 \\
\hline Indústria & 2.987 & 6,0 & 8.721 & 6,5 & 192,0 & \multirow{5}{*}{10} \\
\hline Indústria extrativa mineral & 6 & - & 35 & - & 483,3 & \\
\hline Indústria de transformação & 1.012 & 2,0 & 2.204 & 1,7 & 117,8 & \\
\hline Construção civil & 1.741 & 3,5 & 5.588 & 4,2 & 221,0 & \\
\hline Prod. e distr. de serviços públicos & 227 & 0,5 & 894 & 0,7 & 293,8 & \\
\hline Serviços & 46.973 & 93,6 & 124.179 & 93,2 & 164,4 & \multirow{6}{*}{3} \\
\hline Comércio & 2.372 & 4,7 & 8.933 & 6,7 & 276,6 & \\
\hline Transporte, armazenagem, correio & 1.631 & 3,2 & 3.205 & 2,4 & 96,5 & \\
\hline Serviços de informação & 1.460 & 2,9 & 3.888 & 2,9 & 166,3 & \\
\hline Bancos, seguros e prev. complementar & 5.555 & 11,1 & 13.879 & 10,4 & 149,8 & \\
\hline Atividades imobiliárias, aluguéis & 3.159 & 6,3 & 7.932 & 6,0 & 151,1 & \\
\hline Adm. saúde e educação públicas & 27.092 & 54,0 & 72.493 & 54,4 & 167,6 & 1 \\
\hline Outros serviços* & 5.704 & 11,4 & 13.850 & 10,4 & 142,8 & - \\
\hline Total & 50.200 & 100,0 & 133.235 & 100,0 & 165,4 & 3 \\
\hline Total (preço de mercado) & \multicolumn{2}{|c|}{56.138} & \multicolumn{2}{|c|}{149.906} & 167,0 & \\
\hline
\end{tabular}

Serviços de manutenção e reparação; alojamento e alimentação; serviços prestados às famílias e associações; serviços prestados às empresas; saúde e educação mercantis e serviços domésticos. Fonte: IBGE.

Estas características da esfera econômica distrital, que atuaram (e continuam atuando) sobre a capacidade de atração de migrantes para Brasília, expressaram-se ao longo dos anos em uma peculiar dinâmica de crescimento populacional. 


\section{Aspectos gerais}

A dinâmica populacional de Brasília foi iniciada ainda no período de sua construção, quando foram realizadas amplas campanhas publicitárias pelo governo JK com o objetivo de atrair trabalhadores para a construção da nova capital. Essa campanha coincide com as expressivas taxas de crescimento populacional pelas quais o país passava entre os anos 1950 e 1960. O dinamismo econômico do Distrito Federal foi frequentemente acompanhado pelo crescimento demográfico, na medida em que Brasília se mostrou capaz de atrair para si parte dessas correntes migratórias internas.

Os números da evolução populacional ao longo da história da cidade permitem visualizar o poder de atração da nova capital. Por isso, é interessante aqui buscar visualizar a expansão demográfica e a dinâmica do mercado de trabalho local, pois ambos permitem delimitar aspectos da cultura urbana que se instalou em Brasília e foi responsável por sua consolidação como cidade. Nesse meio século de existência, a capital federal passou de um período sem vida urbana expressiva para uma metrópole que abriga, no total, mais de 2,8 milhões de pessoas distribuídas entre o Plano Piloto e as outras 30 regiões administrativas.

Essa dinâmica demográfica é responsável pelo surgimento dessas regiões administrativas, conhecidas como cidades satélites, bem como pelo crescimento demográfico do Distrito Federal que, devido à sua intensidade, extrapolou suas fronteiras geográficas e políticas. Uma parcela significativa dessa corrente migratória que Brasília atraiu acabou espalhando-se pelos municípios no entorno do Distrito Federal e resultando, com o passar de algumas décadas, num aglomerado urbano com fortes polarizações. O crescimento da região de Brasília e seu entorno superou as expectativas. Atualmente, formam, conjuntamente com a cidade de Brasília, a área metropolitana do Distrito Federal. Essa polarização entre Brasília, cidades satélites e municípios do Entorno ${ }^{8}$ baliza o território. Por causa das diferenças na velocidade de se inserir na lógica do mercado, algumas cidades e municípios apresentaram baixo dinamismo econômico e, por isso, permaneceram praticamente polarizadas por Brasília que se beneficiou dos efeitos indutores de crescimento dali oriundos. Muitas delas tornaram-se áreas dormitório em razão da proximidade com Distrito Federal, na medida em que o custo da terra praticado pelo mercado imobiliário ali foi bastante inferior ao do Distrito Federal, facilitando a moradia de populações com menor renda. Brasília, por esses motivos, torna-se cidade polo em uma área onde são englobados também dez municípios do estado de Goiás sobre os quais exerce influência absoluta9 .
8. O "entorno"

é formado por municípios em áreas limítrofes do Distrito Federal sob jurisdição do governo goiano, porém estreitamente dependentes do Distrito Federal para o trabalho e o acesso a certos equipamentos coletivos nas áreas de saúde, educação lazer. Várias dessas cidades são "cidades dormitórios".

9. Esta influência pode ser comprovada sobretudo no atendimento à demanda por equipamentos de saúde, educação, assistência social, trabalho etc. Os arredores de Brasília cresceram e extrapolaram os limites do quadrilátero do Distrito Federal, chegando às cidades goianas e mineiras, que até então experimentavam um longo processo de estagnação. Este crescimento levou o governo federal a criar, em 1998 mediante lei federal complementar, a Região Integrada de Desenvolvimento do Distrito Federal e entorno (RideDistrito Federal) e que atualmente se apresenta como a quarta maior região metropolitana do Brasil com 3,7 milhões de habitantes. 
O Gráfico 1 permite uma comparação de escalas a partir das dinâmicas demográficas, ao apresentar uma evolução da taxa de crescimento populacional do Distrito Federal, da Região Integrada de Desenvolvimento do Distrito Federal e entorno (Ride-Distrito Federal), da Região Centro-Oeste e do Brasil. Nele é possível constatar que, entre os anos 1950 e 1980, enquanto a população de Brasília e de seu entorno duplicou-se a cada dez anos, o Brasil no seu conjunto cresceu um terço do apurado para essa região. Todavia, na primeira década do século XXI, o crescimento demográfico da área reduziu-se para números que se aproximam da média nacional, apontando uma estabilização do índice médio, o que sugere o esgotamento do boom demográfico inicial e abre possibilidades para uma "janela de oportunidade" no Distrito Federal.

\section{GRÁFICO 1}

EVOLUÇÃO DA TAXA DE CRESCIMENTO POPULACIONAL ANUAL DO DISTRITO FEDERAL, entorno, Ride-Distrito Federal, Centro-Oeste e Brasil (1950 e 2010)

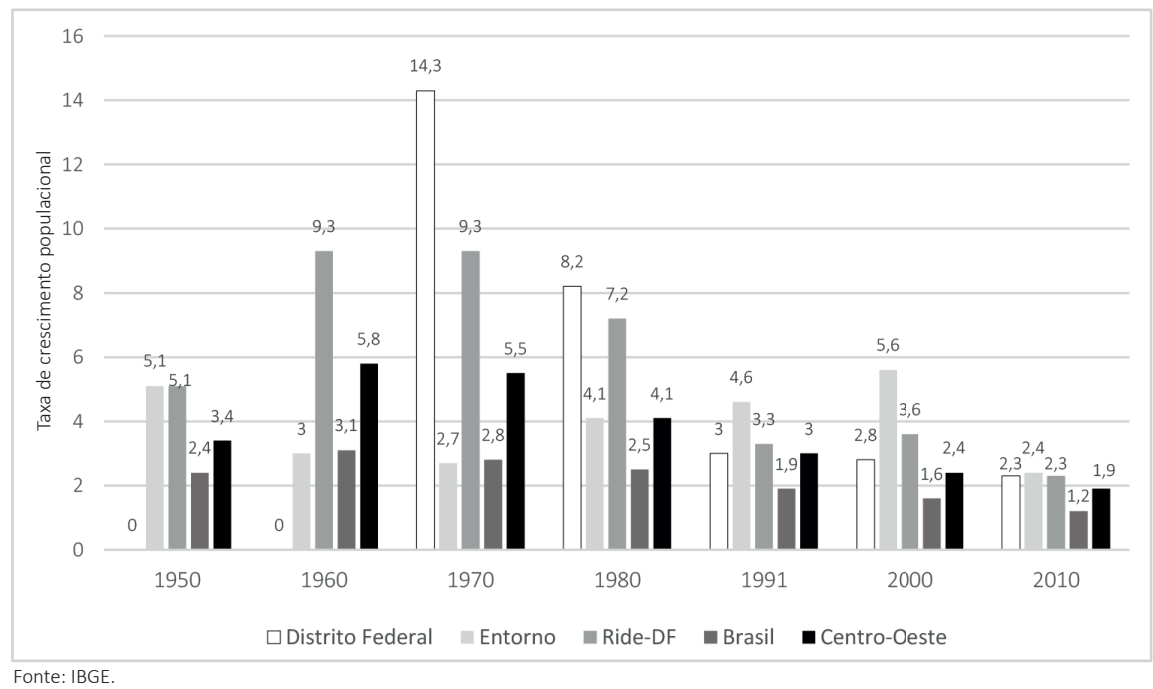

Para analisar as implicações da dinâmica demográfica nos processos de mudança no espaço social da cidade, é recomendável recorrer nessa discussão ao trabalho de Émile Durkheim (1960), pois é possível pensar que o sociólogo francês foi quem mais avançou na análise do papel do fator demográfico na mudança social. Durkheim argumenta que, durante a transição de uma sociedade calcada na solidariedade mecânica para outra baseada na solidariedade orgânica, é possível constatar a influência do fator demográfico na divisão social do trabalho. Para o autor, a forte densidade demográfica propicia as condições para diversificar as funções produtivas, desenvolver a especialização, complementar funções produtivas e intensifica as interações sociais. Quanto mais numerosa a população, mais os indivíduos exercem suas ações uns sobre os outros, mais reagem aos estímulos e com maior rapidez, e assim a vida social se 
intensifica. Ou seja, o aumento da densidade demográfica é uma condição objetiva que permite a passagem de um modelo de sociedade para outro ${ }^{10}$.

Tais proposições são fulcrais para compreender o Distrito Federal. Há elementos para se repensar o intenso fluxo migratório que, dirigido, em certo período, para sua área e seu entorno, altera rapidamente a densidade demográfica. No Distrito Federal há uma realidade peculiar: um funcionalismo público concursado, de um lado; um migrante oriundo do sertão nordestino ou de outra área deprimida do país, de outro. Isso produz um espaço social heterogêneo. Desde sua origem, portanto, o mercado de trabalho local apresentará forte segmentação: por um lado, formado por indivíduos inseridos na lógica mercantil (funcionalismo) e, por outro, grupos de assalariados na iniciativa privada ou autônomos à procura de inserção na lógica salarial. A marcante presença do funcionalismo público adquiriu hegemonia na definição de parâmetros socioculturais no Distrito Federal e entorno na medida em que passou a impor seu estilo de vida peculiar a outros segmentos. Isso irá marcar a rotina cotidiana da cidade, tanto na esfera do mundo do trabalho como também na esfera do "mundo do não trabalho".

No entanto, não se pode negar que as diferentes maneiras de ocupar o espaço físico do Distrito Federal tiveram correlação com a heterogênea origem e condições materiais dos migrantes. Entre o rigoroso planejamento urbano no Plano Piloto ${ }^{11}$, o intenso e desigual surgimento de cidades satélites e a proliferação de condomínios, muitos deles resultado de um processo "selvagem" de apropriação do solo cuja consequência pode ser observada nas diferentes maneiras de ocupação da área. Se, por um lado, o Plano Piloto nasce moderno na sua concepção urbanística, por outro, em sua estrutura social, rapidamente se cria um ambiente contemporâneo com heranças de ambientes tradicionais oriundos do Brasil profundo ${ }^{12}$. O processo de consolidação da cidade como espaço social gerou uma supremacia simbólica a partir do estilo de vida de sua área planejada (Brasília) que, favorecida sobretudo por seu modelo urbanístico, foi responsável por intensificar as interações sociais, mesmo quando se confrontou com uma certa rigidez nas relações intergrupais.

Onde havia grande dispersão e baixo índice de integração econômica, construiu-se uma sólida infraestrutura a permitir a implantação de atividades econômicas ao longo do eixo de polarização da nova capital, influenciando diretamente os núcleos urbanos regionais preexistentes e a região como um todo, o que estabeleceu um polo de forte atração de imigrantes, persistente ainda hoje. Os números provam que ali foi formada uma área metropolitana com dinamismo econômico e elevada influência cultural e política.
10. No nosso caso, a passagem de uma sociedade pré-existente rural para outra de predominância urbana.

11. É condição quase obrigatória o acesso a uma renda monetária para se considerar um morador do Plano piloto.

12. A classe política que se dirige a Brasília, sede dos três poderes da nação, é oriunda de todo o país. Aqui chegando, trazem suas estratégias de poder para a cidade que passa a refletir aspectos peculiares de diferentes práticas políticas regionais do país. A corrupção na esfera pública talvez seja a mais perfeita materialização desse fenômeno. 


\section{Um tipo ideal de cidade?}

O modelo inicial de Brasília é quase um "tipo-ideal" de cidade nos moldes de Max Weber (1979). É de se ressaltar, certamente, que para ele só se pode falar de "cidade" no sentido econômico, ou seja,

quando a população local satisfaz uma parte economicamente essencial de sua demanda diária no mercado local e, outra parte essencial também mediante produtos que os habitantes da localidade e a povoação dos arredores produzem ou adquirem para colocá-los no mercado (Weber, 1979: 69).

Nas primeiras décadas, Brasília foi quase exclusivamente, e na sua precariedade, uma cidade-Estado. Isso irá se manifestar no seu mercado de trabalho praticamente monopolizado pelo emprego no setor público, cuja influência se estende pelos demais setores da economia e na indústria da construção civil. Nesse particular, a cidade que já nasceu como centro terciário se antecipará no tempo à nova configuração do fenômeno urbano, a se consolidar mais à frente, com as transformações estruturais que o capitalismo apresentará com a globalização.

Há ainda outro aspecto: por sua característica de cidade-Estado, Brasília surge completamente inserida na lógica monetária, ou seja, circula entre seus moradores uma massa salarial expressiva na medida em que vão sendo transferidas para a cidade as instituições públicas dos três poderes do Estado (Executivo, Legislativo e Judiciário). Trata-se de um aspecto que, pelo simples fato de sua existência e pela ação que exerce, é capaz de gerar ou produzir mudanças.

Há, portanto, um fator estratégico que, muito embora seja aparentemente banal, é fundamental para compreender a velocidade com que o núcleo original rapidamente se transforma em núcleo urbano, no sentido econômico e sociológico do termo. Vejamos isso mais de perto.

13. A abertura, por exemplo, de um edital para concurso público de uma instituição estatal sediada na cidade (Congresso Nacional, Banco Central etc) injeta, uma vez contratados os aprovados, milhões de reais mensais na economia local.
Na esfera econômica, cada nova instituição que se transfere para Brasília traz consigo um grupo de funcionários a dinamizar o mercado local ${ }^{13}$, já que são agentes públicos com estabilidade no emprego e donos de uma renda mensal segura e relativamente elevada. A assertiva weberiana segundo a qual a "cidade é um local de mercado" pode ser claramente percebida em Brasília.

De uma perspectiva propriamente sociológica, a população distrital aos poucos se diversifica com a chegada também de migrantes alheios ao serviço público, porém atraídos pelo potencial de expansão do mercado de trabalho local. Como se pode observar, o Distrito Federal se caracteriza, desde as origens, como espaço de per- 
manente mudança social, a tal ponto que nos seus primeiros anos de existência se constata um ritmo acelerado de crescimento tanto populacional como em relação às diferentes atividades econômicas.

Cabe colocar algumas questões que poderiam discernir o processo de consolidação de Brasília como centro urbano. Primeiramente, por se tratar do espaço urbano da cidade, em permanente mudança, "o que muda" na cidade e em sua dinâmica? A resposta a esta questão pressupõe inicialmente delimitar os setores (ou as esferas) da lógica urbana que vivenciam diferentes formas de transformações. Em outras palavras, nesses quase 55 anos de existência, qual mudança em Brasília pode ser digna de destaque?

Pensamos que há na relação espaço/sociedade alguns aspectos que podem ser tratados na procura de respostas a este ponto. Já fizemos referência acima ao forte crescimento populacional que ocorre no Distrito Federal desde a fundação de Brasília e ao seu papel na diversificação das atividades e do mercado de trabalho na cidade. Vejamos agora, com um pouco mais de detalhes, alguns impactos sobre o conjunto da rede urbana microrregional polarizada por Brasília.

\section{Plano Piloto, satélites e entorno: lógicas contraditórias ou complementares?}

O contexto urbano muito facilmente avança para algo que se pode denominar de "grande cidade" (área central: o Plano Piloto e o subúrbio próximo das satélites; o entorno do Distrito Federal: o subúrbio distante). Pierre Bourdieu (1997) é útil nessa discussão por nos alertar sobre o risco de falarmos sobre "subúrbio com problemas" quando usualmente tratamos de realidades amplamente desconhecidas. Um discurso geralmente pode ser alimentado por imagens ou palavras mais ou menos não controladas, como aquelas que a imprensa sensacionalista e a propaganda ou o boato político veiculam. Esse cuidado precisa ser redobrado quando se trata das cidades satélites (e mais recentemente do "entorno") do Distrito Federal. Por serem áreas urbanas fora da lógica do planejamento físico que define o Plano Piloto e estar em uma posição subordinada frente a ele, muitas vezes alguns analistas costumam agir com "atenção duvidosa". O desinteresse em tratá-las analiticamente termina por favorecer ainda mais essa imagem distorcida do senso comum - que, no nosso caso, é de que se trata de uma área com precariedade geral -, alimentada sobretudo pelas diferentes mídias (jornais, TV, rádio etc).

A Figura 1, ilustra a segregação socioespacial entre as 30 Regiões Administrativas existentes a partir da distribuição desigual da renda no Distrito Federal. O cinturão que circunda o Plano Piloto, formado pelos Lagos Norte e Sul, Sudoeste e Park Way, é detentor das maiores rendas médias, criando uma ilha de prosperidade com altos ren- 
FIGURA 1

RENDA MÉDIA DOMICILIAR MENSAL EM SALÁRIOS MÍNIMOS (SM), POR REGIÃO ADMINISTRATIVA DO DISTRITO FEDERAL PARA 2008

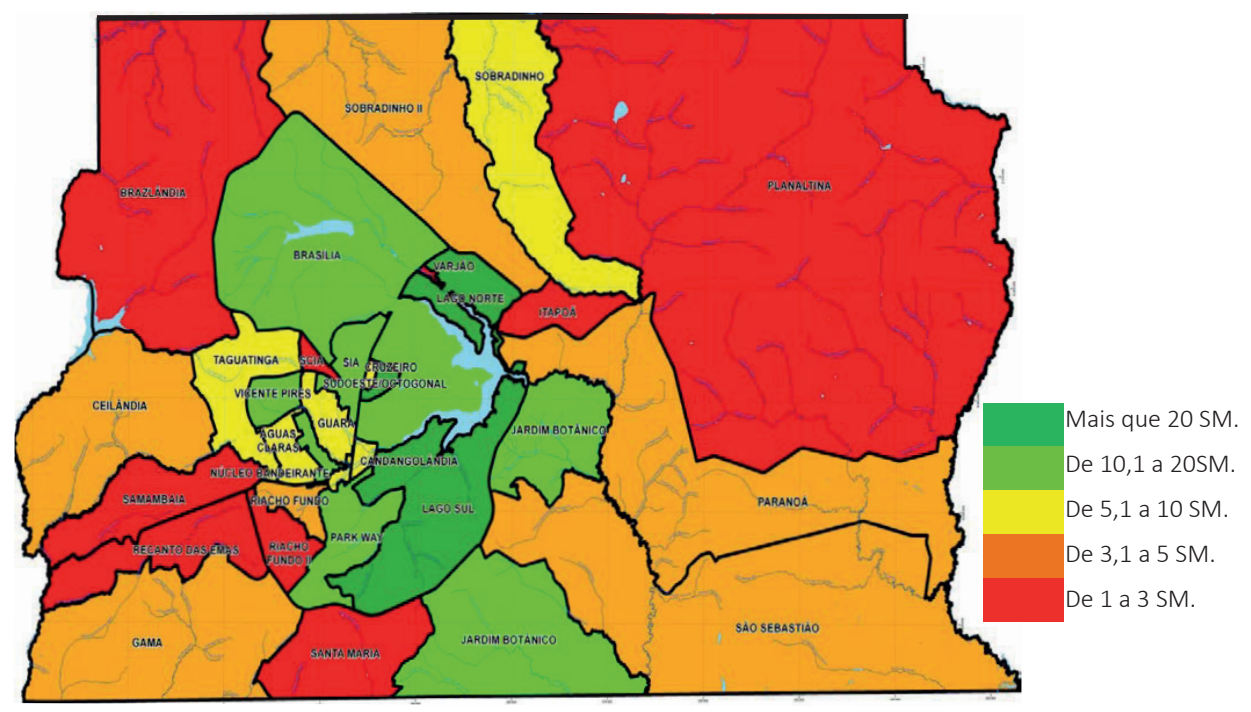

Fonte: Codeplan, 2008

dimentos no coração do Distrito Federal. À medida que nos afastado Plano Piloto, o rendimento médio cai em periferias em expansão cada vez mais pauperizadas, já que os rendimentos são cada vez menores. Nota-se que, com algumas exceções, como a Estrutural (que surgiu como periferia próxima ao Plano Piloto), as zonas de exclusão social se posicionam em locais cada vez mais distantes da área central e planejada do Distrito Federal.

A Tabela 2 mostra que renda e funcionalismo público andam juntos. As cidades que concentram maior número de funcionários públicos tendem a apresentar rendas médias mais elevadas que as demais. O Plano Piloto e adjacências (Lagos Norte e Sul, Sudoeste, Cruzeiro, Guará, Jardim Botânico, Águas Claras e Park Way) embora abriguem apenas cerca de $25 \%$ da população total do Distrito Federal, concentram 51\% dos postos da administração pública e renda média domiciliar mensal superior a 19 salários mínimos. As demais Regiões Administrativas, contudo, com 75\% da população, reúnem $49 \%$ dos postos de trabalho no serviço público e renda média domiciliar de 5,6 salários mínimos.

O Distrito Federal se desvenda, portanto, na representação construída a partir da homogênea realidade do Plano Piloto e das áreas limítrofes, não somente como bloco homogêneo, mas como um universo com fortes doses de heterogeneidade física, econômica, social e cultural. Entre a Vila Estrutural e Águas Claras, passando por Tagua- 
TABELA 2

POPULAÇÃO OCUPADA SEGUNDO O SETOR DE ATIVIDADE REMUNERADA

E RENDA MÉDIA DOMICILIAR, POR REGIÃO ADMINISTRATIVA (2010-2011)

\begin{tabular}{|c|c|c|c|c|c|c|c|c|}
\hline 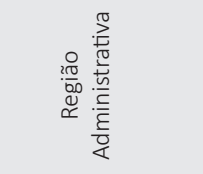 & 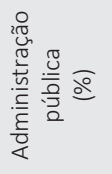 & $\begin{array}{l}\frac{0}{2} \\
\frac{0}{2} \\
\frac{0}{2} \\
\frac{0}{0} \\
\frac{0}{0} \\
\frac{0}{00} \\
0\end{array}$ & 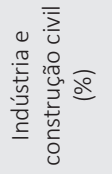 & 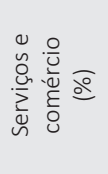 & 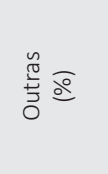 & 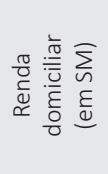 & 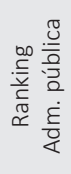 & 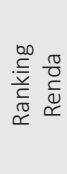 \\
\hline Distrito Federal & 22,70 & 0,60 & 6,40 & 54,20 & 16,10 & 8,52 & - & - \\
\hline Sudoeste/ Octog. & 54.40 & 1,40 & 1,90 & 25,80 & 16,50 & 19,8 & Io & 50 \\
\hline Lago Norte & 48,00 & 0,70 & 2,40 & 27,00 & 21,90 & 23,4 & 20 & 29 \\
\hline Brasília & 46,10 & 0,60 & 1.20 & 31.60 & 20.60 & 17,6 & 3응 & 60 \\
\hline Jardim Botânico & 42,60 & 0,40 & 3.60 & 35,20 & 18.20 & 21,8 & $4 \stackrel{0}{2}$ & 3응 \\
\hline Cruzeiro & 39,10 & 0,40 & 1.60 & 39,40 & 19,50 & 12,3 & 50 & 80 \\
\hline Águas Claras & 36,60 & 1,20 & 5,10 & 48,90 & 8,20 & 13,4 & 60 & 70 \\
\hline Park Way & 33,70 & 1,20 & 2,80 & 39,10 & 23,20 & 21,3 & 70 & $4 \stackrel{0}{0}$ \\
\hline Guará I e II & 30,80 & 0,20 & 3,00 & 50,20 & 15,70 & 11,1 & 80 & 10 \\
\hline Lago Sul & 30,20 & 0,60 & 3,20 & 40,10 & 25,90 & 31,6 & 9o & 10 \\
\hline Sobradinho I & 27,30 & 0,70 & 3,50 & 48,40 & 20,00 & 9,0 & 10 & 110 \\
\hline Vicente Pires & 27,10 & 0,30 & 6,00 & 53,50 & 13,20 & 11,8 & 11 & 9o \\
\hline Sobradinho II & 23,50 & 0,00 & 8,20 & 48,70 & 19,60 & 9,0 & $12^{\circ}$ & $12 \circ$ \\
\hline Taguatinga & 22.80 & 0,40 & 3,10 & 58,20 & 15,40 & 8,5 & $13 ㅇ$ & 130 \\
\hline Gama & 21,30 & 0,20 & 5,10 & 61,10 & 12,40 & 6,5 & 14 & 160 \\
\hline N. Bandeirante & 19,50 & 1,00 & 2,80 & 58,80 & 17,90 & 8,3 & 150 & 140 \\
\hline Candangolândia & 19,30 & 0,50 & 4,20 & 57,70 & 18,40 & 7,4 & 160 & 150 \\
\hline Riacho Fundo I & 18,80 & 0,10 & 7,20 & 58.90 & 15,10 & 6,2 & 170 & 170 \\
\hline Brazlândia & 15,70 & 2,60 & 6,90 & 63,30 & 11,60 & 4,6 & $18^{\circ}$ & 190 \\
\hline Santa Maria & 14,40 & 0,60 & 7,20 & 61,80 & 15,90 & 4,5 & 190 & 200 \\
\hline Planaltina & 14,40 & 0,40 & 11,60 & 56,40 & 17,20 & 4,3 & $20 \cong$ & $21^{\circ}$ \\
\hline Ceilândia & 12,20 & 0,70 & 8,30 & 66,90 & 11,90 & 4,7 & $21 ㅇ$ & 180 \\
\hline Samambaia & 11,20 & 0,10 & 7,80 & 63.60 & $17,30^{\prime \prime} / 0$ & 4,1 & 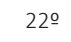 & 230 \\
\hline Riacho Fundo II & 10,30 & 0,40 & 11,00 & 64,40 & 14,00 & 4,3 & $23 ㅇ$ & 22 \\
\hline Recanto das Emas & 9,90 & 1,00 & 9,80 & 62,70 & 16.70 & 3,6 & 240 & 250 \\
\hline Paranoá & 7,50 & 0,10 & 12,30 & 62,50 & 17,60 & 3,6 & 250 & 240 \\
\hline São Sebastião & 5,60 & 0,20 & 12,20 & 60,10 & 21,90 & 3,4 & 260 & 260 \\
\hline Varjão & 4,70 & 0,10 & 10,40 & 67,60 & 17,00 & 2,9 & 270 & 270 \\
\hline SCIA (Estrutural)* & 2,90 & 0,10 & 15,40 & 59,70 & 21,90 & 2,3 & 28 & 290 \\
\hline Itapoã & 2,70 & 0,30 & 19.90 & 59,10 & 17,90 & 2,5 & 29 & 280 \\
\hline SIA** & - & - & - & - & - & - & - & - \\
\hline
\end{tabular}

* SCIA: Setor Complementar de Indústria e Abastecimento, inclui a Vila Estrutural.

** SIA : Setor de Indústria e Abastecimento. É uma RA do Distrito Federal que abriga somente indústrias e serviços. Não possui população residente.

Fonte: Codeplan/PDAD 2010-2011. 
14. De fato, uma das poucas atividades que junto com a administração federal ainda se concentra maciçamente no Plano Piloto é a oferta de equipamentos culturais (museus, cinemas, teatros) quase inexistentes nas satélites além obviamente, dos equipamentos de saúde de alta complexidade.

\section{Para uma} discussão a respeito, ver Os donos do poder, de Raymundo Faoro.

16. Estamos tratando o "regime político" considerando as forças hegemônicas que assumem o poder do Estado e que são as responsáveis pelo governo em períodos determinados. Assim, se somos um Estado capitalista, há distinções entre um Estado nas mãos de um PSDB e outro nas mãos de um PT, por exemplo. Aqui estaria a natureza do regime político diferenciado entre um e outro governo.

17. Mesmo se no Brasil o Legislativo é mais um braço da gestão política que se apresenta como "amarrado "ao Poder Executivo, há ainda entre eles uma autonomia relativa que garante mesmo aos parlamentares os meios de barganhar decisões, num jogo do "toma lá, dá cá". tinga, Guará, Ceilândia, Paranoá etc., há um leque com forte diversificação entre suas diferentes realidades, todas submetidas ao monopólio de representação exercido pelo Plano Piloto. No entanto, o espaço social das satélites (e do entorno) se apresenta como território espontâneo de agentes individuais e de grupos, com diferentes possibilidades de acesso a bens coletivos urbanos ${ }^{14}$. E esta hegemonia do Plano Piloto, observada no âmbito do Distrito Federal como "tipo-ideal" de cidade, tem no setor público a sua base de sustentação: emprego estável, salários relativamente elevados, funções administrativas de prestígio, que garantem status, sobretudo frente aos habitantes não funcionários públicos.

\section{Funcionalismo público em Brasília: entre meritocracia e clientelismo}

Os critérios de recrutamento do funcionalismo público no Brasil seguem determinações da Constituição Federal de 1988 (Art. 37) que estipula a contratação para vagas disponíveis através de concurso público. Em princípio, todos teriam direito de concorrer, desde que atendessem às características da função definidas por editais públicos. Por detrás dessa exigência, é possível encontrar o princípio (primazia) da meritocracia que objetivava substituir o tradicional clientelismo e a prática do nepotismo na ocupação dos cargos da administração estatal que foi muito usada em períodos anteriores (Brasil colônia, século XIX e parte do século XX) ${ }^{15}$. Entretanto, os mais altos postos da função pública ainda são ocupados a partir de um forte jogo político-partidário, no qual critérios técnicos de competência não são necessariamente os mais utilizados. Essa é uma dimensão da função pública que produz efeitos perversos entre o funcionalismo. O status no trabalho termina sendo, muitas vezes, mais resultado de relações pessoais de "compadrio" ou de lealdade política, do que propriamente de competência para o exercício da função.

No Estado brasileiro não podemos, portanto, falar em "administração", mas em "ministérios". O fato é que a organização administrativa varia não apenas em razão de alterações no regime político ${ }^{16}$, mas dos diferentes ministérios. Embora Charle (1980: 216) tenha analisado a burocracia francesa no século XIX, por aproximação, é possível utilizar seus argumentos para refletir sobre a sociedade presente no Plano Piloto. Ao tomar por base a análise desse autor, percebe-se que há no Plano Piloto mais do que uma administração estatal. O que se tem é uma administração ministerial, sujeita a mandos e desmandos de autoridades superiores, ou se submetendo a decisões do legislativo ${ }^{17}$. O planejamento estatal que definiria, em tese, os rumos a seguir pelo conjunto dos ministérios e traria harmonia entre meios e fins nunca foi integralmente colocado em prática, dadas as ingerências políticas que caracterizam a implementação de políticas públicas. Mesmo assim, a hegemonia do setor público, nos rumos que a cidade percorre ao longo de sua existência, tem mais relação com a posição 
que ocupam seus integrantes na hierarquia administrativa do que propriamente com o volume ou o quantitativo de seus integrantes.

Interessa aqui ressaltar o embaralhamento do jogo social classificatório que decorre destas características do funcionalismo público no Brasil e, particularmente, em Brasília, que redunda em diferentes critérios de determinação do status. Por um lado, a administração federal no Brasil caracteriza-se por uma inquietante prática de corrupção nos altos escalões, onde, rotineiramente, escândalos veem à tona, trazendo fissuras na imagem do funcionalismo, sobretudo na sua imagem ideal de "alguém a serviço do cidadão". Por outro, com esta imagem arranhada, o que aparece em Brasília com mais solidez é, sem duvida, o lugar de trabalho e moradia, alternativas capaz de garantir status. Trabalhar na Esplanada dos Ministérios e ter domicílio nas áreas nobres funciona como símbolos de prestígio social e de status ${ }^{18}$. Por outro lado, morar no Plano Piloto e nas áreas limítrofes significa, aos olhos dos não moradores, um ganho simbólico de expressão, dadas as externalidades que o endereço garante, mesmo quando se sabe que a especialização administrativa e as funções técnicas se consolidam lentamente. Há aí a expressão límpida da importância do endereço na definição do status social que está acima de critérios objetivos como renda, educação, posição funcional etc. ${ }^{19}$.

Importa ressaltar novamente que os empregos de alto nível no aparelho de Estado são ocupados muitas vezes mais por critérios políticos do que competência, sendo poucas as carreiras públicas que de fato seguem tais pressupostos sobretudo na cúpula do funcionalismo. Assim, o alinhamento da alta função pública com base no modelo meritocrático vem se dando de maneira instável, lenta, sujeita a conjunturas políticas que muitas vezes a desviam de seu rumo. Em razão disso, morar no Plano Piloto ganha força no sistema classificatório e atua positivamente no sistema social geral de classificação na cidade, favorecendo ganhos de status que se soma àquele adquirido na vida profissional.

Ocorre em Brasília outro fenômeno peculiar que foi tratado por Charle (1980: 216). Ao analisar aspectos ligados ao mérito e a antiguidade, o autor ressalta que nas esferas mais burocratizadas do funcionalismo tais critérios são recorrentes; porém, quando se trata de postos de trabalho mais raros do alto escalão e mais atrativos, os fatores sociais e sobretudo políticos são importantes, embora aqueles que os ocupem se vangloriem de que acederam aos postos por mérito. Trata-se, portanto, de um ambiente cuja via para ocupar os cargos é em geral o concurso público. No entanto, o jogo de status no alto escalão se faz por critérios variados, a partir da posição social que o indivíduo ocupa.

A cidade e sua cultura são ainda recentes para pressupormos que haja tradições consolidadas. Já é contudo possível perceber que, para certos cargos e funções, as refe-
18. Um dos indicadores da alta atração que o emprego público exerce sobre o imaginário da população por oferecer elevado prestígio é a proliferação de cursinhos preparatórios para concursos existentes na cidade e sempre com elevada procura por vagas.

19. No interior do próprio Plano Piloto funcionam também critérios classificatórios de status segundo o endereço residencial. Além das antigas quadras funcionais (Congresso, Banco Central, Banco do Brasil etc.) há distinções entre elas pelo padrão das construções. Porém, a imagem para o público externo ao Plano Piloto, é de um território socialmente homogêneo. 
rências familiares já começam a ser notadas. De qualquer maneira, a ocupação de postos elevados no aparelho de Estado em Brasília oferece a estes altos funcionários o que Charle (1980: 220) chama de "capital de relações sociais", que cada qual procura utilizar da melhor forma, segundo os seus interesses individuais. Tudo parece indicar que a cidade tende a reproduzir padrões culturais tradicionais. Essa inclinação latente de reprodução de padrões tradicionais e essa assimetria entre espaço social tradicional e espaço físico moderno podem ser um dos entraves a processos de mudança na cidade. Surge portanto uma indagação: a cidade, por suas características de capital política, pode aspirar a outras funções que transcendam às burocráticas por mais importantes que estas sejam?

As características que, em geral, se aplicam às chamadas cidades globais, embora não exclusivas, têm uma certa ênfase no seu principal setor econômico e, por consequência, no perfil socioprofissional de parcela de sua população. Ainda em fase de afirmação diante da rede urbana brasileira, Brasília tem no setor público o principal fator de sua identidade. Cabe, então, perguntar até que ponto a hegemonia do setor público configura sua cultura peculiar. E desse modo poderíamos verificar se este setor ainda é determinante na representação que a cidade produz para seus moradores e para o público externo ao núcleo central do Distrito Federal. Estamos nos referindo, portanto, a um grupo que, além de uma história antiga dentro do aparelho do Estado brasileiro, goza de estabilidade garantida por uma hierarquia fomentada entre eles e por uma carreira lenta, porém segura. Esse conjunto de elementos confere a esse grupo uma postura peculiar.

É importante deixar registrado que a burocracia é um grupo hierarquizado, no qual a adaptação de cada indivíduo ao espírito da administração pública é heterogênea. $A$ recorrente abertura de novas vagas ocupacionais no setor público permite o ingresso de novos quadros, muitos dos quais não interiorizaram previamente o ethos de "bom funcionário". E é possível acrescentar que essas pessoas têm pouca chance de redefinir comportamentos sociais da categoria. Em geral, altos postos na hierarquia da administração vêm acompanhados por altos ganhos monetários e benesses extras do Estado, o que permite um padrão de vida bem acima da média da população. Podemos considerar que, no geral, os altos funcionários se arvoram o direito de esperar retribuições materiais e simbólicas proporcionais às responsabilidades assumidas e às funções ocupadas.

Ainda que esse grupo detenha a hegemonia na configuração dos parâmetros da cultura de Brasília, é preciso considerar a heterogeneidade ou a diversidade interna ao próprio grupo que com frequência está afastado de um "Brasil profundo" que ainda caracteriza a Região Centro-Oeste. Apesar dessa hegemonia do setor público, a dinâmica populacional do Distrito Federal e entorno o ultrapassa enormemente. Ao 
considerar o Distrito Federal e a expansão do entorno, há um processo histórico de crescimento populacional peculiar, conforme demonstrado anteriormente. No entanto, o crescimento demográfico e o poder de atração que a capital federal exerce não podem ser explicados apenas pela oferta de vagas (limitadas) na burocracia estatal. Esta dinâmica demográfica indica uma expansão que transcende a estímulos reais do setor público e de sua capacidade de absorver o crescimento demográfico em seus quadros.

Nossas assertivas estão ainda com elevado nível de abstração e necessitam de uma concretização que pode ser alcançada com dados sobre a participação relativa das diferentes atividades econômicas e categorias socioprofissionais no Distrito Federal. A Tabela 3 mostra que, nos últimos dez anos, o segmento de atividade econômica que obteve o menor crescimento em relação ao quantitativo de empregos disponíveis foi aquele voltado para a administração pública, cujo crescimento foi de $29 \%$, enquanto a indústria e a construção civil cresceram $112 \%$ e os segmentos de comércio e serviços apresentaram alta de $61 \%$ no mesmo período. Ou seja, é notável que há toda uma cadeia de processos produtivos que vem ocorrendo no Distrito Federal e seu entorno e que funciona descolada da lógica da burocracia estatal. Ao mesmo tempo, a dependência da máquina estatal permanece. Embora exista apenas $29 \%$ da população economicamente ativa empregada na administração pública, este segmento é responsável por 54\% do PIB local.

\section{TABELA 3}

ESTIMATIVA DO NÚMERO DE PESSOAS OCUPADAS

POR SETOR DE ATIVIDADE ECONÔMICA - DISTRITO FEDERAL 2000-2011 (EM MILHARES)

\begin{tabular}{|c|c|c|c|c|c|c|c|c|c|c|c|c|c|}
\hline $\begin{array}{l}\text { Setores da } \\
\text { economia }\end{array}$ & 2000 & 2001 & 2002 & 2003 & 2004 & 2005 & 2006 & 2007 & 2008 & 2009 & 2010 & 2011 & $\begin{array}{c}\text { Var } \% \\
2001 / 11\end{array}$ \\
\hline Serviços & 408 & 409 & 489 & 502 & 545 & 565 & 604 & 536 & 536 & 590 & 593 & 637 & 56,3 \\
\hline Adm. pública & 158 & 160 & 177 & 185 & 179 & 195 & 171 & 176 & 188 & 198 & 205 & 204 & 29,4 \\
\hline Comércio & 105 & 111 & 138 & 143 & 161 & 171 & 159 & 177 & 180 & 188 & 18) & 192 & 82,1 \\
\hline Construção civil & 28,8 & 27,6 & 36,1 & 29,6 & 35,1 & 36,4 & 48,2 & $\mathrm{SI}$ & 56 & 60 & 69 & 71 & 146,5 \\
\hline Ind. transformação & 26,8 & 27,8 & 31,5 & 32,4 & 31,8 & 35,6 & 40,8 & 42 & 49 & 42 & 52 & 47 & 75,3 \\
\hline Outros* & 4,7 & 7,6 & 10,2 & 9,1 & 7,7 & 8,8 & 10,5 & 114 & 115 & 110 & 103 & 103 & $2.091,0$ \\
\hline Total & 731 & 743 & 882 & 901 & 960 & 1.012 & 1.034 & 1.096 & 1.151 & 1.188 & 1.206 & 1.235 & 71,4 \\
\hline
\end{tabular}

* Serviços domésticos, agricultura, pecuária, extração mineral e vegetal; embaixadas, consulados, representações e outras atividades não classificadas

Fonte: PED/Distrito Federal (Sedest/GDistrito Federal, Dieese e Seade/SP). Apoio Ministério do Trabalho e Emprego (MTE) e Fundo de Amparo ao Trabalhador (FAT).

Enquanto algumas regiões do Distrito Federal são formadas essencialmente por funcionários públicos, há outras que vêm se consolidando e se dinamizando a partir de lógicas diferentes. Embora o Plano Piloto ainda concentre grande parte dos equipamentos urbanos de lazer e de cultura, e continue se destacando como principal polo de emprego e renda do Distrito Federal, Regiões Administrativas como Taguatinga, 
POPULAÇÃO OCUPADA POR REGIÃO AdMINISTRATIVA. despontando no cenário da capital

PLANO PILOTO E DEMAIS RAS

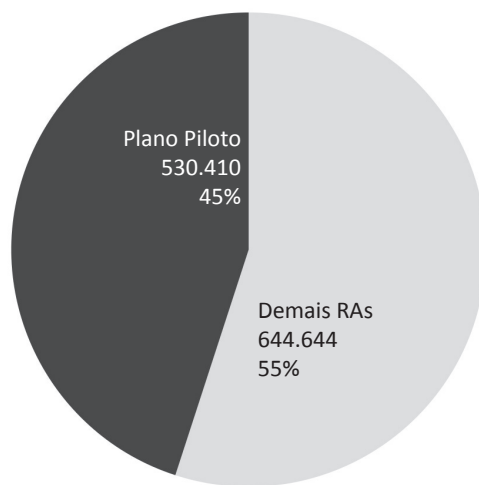

Fonte: PDAD/ Codeplan (2011-2012). federal como importantes polos econômicos sub-regionais.

O Gráfico 2 apresenta os dados referentes aos locais de trabalho da população do Distrito Federal, numa comparação entre Plano Piloto e demais RAs, e mostra que o Plano Piloto tem cerca de 530 mil postos de trabalho, o que representa cerca de $45 \%$ de todas as vagas de emprego da região, enquanto que sua população é de 214 mil pessoas

( $8,5 \%$ da população do Distrito Federal). Isso implica que, para cada morador do Plano Piloto, existem 2,5 postos de trabalho. Mas os dados permitem ver ainda que existe uma vida pulsante nas chamadas cidades satélites que já concentram $55 \%$ de todos os postos de trabalho e apresentam relativo dinamismo, como indica a quantidade de

20. Cabe ainda destacar que a região central do Plano Piloto é altamente diversificada e concentra uma série de serviços especializados: clínicas, hospitais, escritórios de profissionais liberais, shopping centers, universidades, museus, grandes redes de supermercado e extensa rede bancária. empregos nelas gerados ${ }^{20}$.

\section{Considerações gerais:}

\section{esboço sobre potencial de inserção de Brasília na rede mundial de cidades}

A análise apresentada nas páginas anteriores demonstra algumas características da metrópole Brasília que nos auxiliam no sentido de delinearmos nossa hipótese de que a área urbana do Distrito Federal preenche alguns aspectos para uma potencial cidade global. Elegemos alguns aspectos que nos subsidiam nessa direção: a economia local, a dinâmica populacional e as implicações sobre o perfil da população capitaneada pela característica de uma cidade-Estado.

Insistimos também sobre o desenho urbanístico de seu núcleo central que capitaneia um imaginário urbano peculiar. Chama atenção de início a vitalidade econômica da área, detentora de forte dinamismo. Outro aspecto que se deduz da análise é que aqui - como, de resto, nas demais metrópoles contemporâneas - a produção e apropriação do território formam um todo constituído por partes com lógicas diferenciadas visualizadas na própria morfologia do território das cidades que compõem a metrópole. Afora um Plano Piloto com um urbanismo radicalmente racional, o que se tem nos demais sítios urbanos da área são variados padrões de ocupação do território formando "fragmentos", cada qual com sua dinâmica própria. Nessa metrópole obser- 
vamos ainda regiões administrativas que buscam conquistar maior grau de autonomia frente à intensa polarização exercida pelo Plano Piloto.

Aquela imagem original de Brasília, na qual destinavam as satélites para o baixo escalão da administração pública e nas quais eram enviados os "indesejáveis", é cada vez menos evidente. A lógica urbana alastrou-se por estes territórios de forma a conferir-lhes destaque na própria rede de cidades do país. Esse dinamismo urbano tem caráter desigual, basta observarmos - com as exceções de praxe - que as populações de baixa renda estão se dirigindo para a periferia cada vez mais distante, ocupando as terras limítrofes do estado de Goiás, o chamado entorno.

Vale ressaltar ainda que mesmo se Brasília nasceu sob o signo do planejamento racional, observa-se aqui a fragmentação territorial, ou seja, um território urbanizado de forma fracionada cuja ocupação se dá de forma extensiva nos primeiros anos (expansão horizontal) e atualmente começa a experimentar uma ocupação intensiva (verticalização). O fenômeno é também recorrente em outras metrópoles do país, como a criação de novas centralidades diferentes da funcionalidade do Plano Piloto, as quais impõem agora um uso diversificado do território que se contrapõe à lógica da origem.

Vejamos algumas implicações de nossa análise. Primeiramente é preciso chamar atenção para o fato de que o modelo de urbanismo que se implantou no Plano Piloto, baseado no modernismo da primeira metade do século XX, está em desuso nos tempos atuais. Entretanto, dado o tombamento da área e as suas qualidades urbanísticas, Brasília tornou-se o lugar de moradia de indivíduos com nível de renda e de status elevados. Ao mesmo tempo, nossa análise apontou que a valorização da atividade burocrática está cada vez mais no plano da representação, pois os dados mostram que outros setores econômicos vêm ganhando espaço na cidade. Ao mesmo tempo, esse discurso de valorização do setor público que pressupõe um bloco social homogêneo não especifica o que existe: um conjunto de indivíduos socialmente diferenciados. Esse discurso está amparado no fato de que uma parcela importante de seus componentes tem no endereço (Plano Piloto) um dos critérios classificatórios de maior prestígio dentro do espaço social do Distrito Federal. Morar, portanto, no Plano Piloto, onde habita principalmente funcionários públicos, é um fator que concorre para a construção da representação social de seus habitantes. Em outras palavras, o lugar de moradia aparece como privilégio face, sobretudo, às condições urbanas, sociais e econômicas de inúmeras cidades satélites que não conseguem ainda atingir os padrões urbanísticos da área central.

O tombamento pela Organização das Nações Unidas para a Educação, a Ciência e a Cultura (Unesco) e posteriormente pelo Instituto de Patrimônio Histórico e Artístico Nacional (Iphan) do Plano Piloto de Brasília garante a conservação do sítio central 
21. Provavelmente, caso fosse permitido a construção de espigões no Plano Piloto, não teria acontecido Águas Claras, uma das atuais RAs do Distrito Federal. do Distrito Federal que, ao que tudo indica, engessa a estrutura física atual e a protege dos interesses, sobretudo, do capital imobiliário e mesmo de certas correntes da arquitetura brasileira que aspiram maior liberdade de intervenção no espaço da cidade ${ }^{21}$. Assim, enquanto a percepção sobre cidades vem sofrendo alterações, sobretudo a partir da hegemonia do mercado na concepção utilitarista do mundo contemporâneo, Brasília permanece "fora" dos arroubos atuais de espaços urbanos, tão bem ilustrado pelas megaconstruções em cidades do Oriente Médio e Ásia (Dubai, Xangai, Ho Chi Min, Kuala Lampur, Mumbay, Johannesburg etc.).

É importante fazer esta relação, pois o afluxo de grandes projetos arquitetônicos nessas cidades da Ásia e Oriente Médio - eixo atual da dinâmica capitalista - aponta para uma nova lógica urbana em termos globais. Se durante séculos as grandes capitais foram centros de poderes rivais, hoje, a geopolítica da mundialização desenha um planeta multipolar onde as capitais políticas são induzidas a agir em interação. Em outros termos, saímos das cidades-fortalezas para as cidades-redes. Na América Latina, afora três ou quatro grandes metrópoles no continente (Cidade do México, São Paulo, Buenos Aires, Rio de Janeiro), ainda estamos relativamente tímidos na participação dessa nova concepção das metrópoles inseridas na rede mundial de cidades. Por outro lado, e conforme Dagorn (2009), as cidades políticas hoje são herdeiras da concepção do poder do Estado-nação do século XIX e elas estendem seu poder em função de sua influência geopolítica. A globalização nos tempos atuais promove a cooperação entre mercados, indicando que está em curso a construção de uma rede de cidades, fortemente interligadas entre elas, na qual, a América Latina deve inserir-se.

Nesses tempos em que as metrópoles são peças estratégicas nos jogos de poder em escala internacional, muitas delas concorrendo ou mesmo ultrapassando o poder do Estado, em Brasília, ao contrário, o agente estatal é um aliado privilegiado nas perspectivas futuras de expansão da cidade. Isso porque, ao risco de se acomodar em seu papel político usual, a dinâmica da cidade vem apontando-Ihe novos rumos que se somam ao de capital política. Se isso se comprovar, Brasília, como capital política e com sua dinâmica econômica cada vez mais diversificada, começará a participar desta rede mundial de cidades com relativo peso, proveniente sobretudo da posição do Brasil no cenário internacional. Em outros termos, decisões tomadas em Brasília têm impacto sobre todo o território nacional e em certa medida nos fóruns internacionais onde o Brasil tem assento, evidenciando um poder expandido sobre a nação.

Sabemos que as complexas dinâmicas exigidas pelas diversas formas de organização social e econômica estão produzindo e reproduzindo o poder a partir de sítios pilotos, localizados em algumas grandes cidades, como as cidades globais para usar o termo de Sassen (1999). Embora Brasília não tenha ainda o porte de uma metrópole mundial, podemos nos antecipar e tentar perceber até que ponto ela caminha nes- 
sa direção ${ }^{22}$. As cidades globais se tornaram a referência nos debates prospectivos internacionais organizados em torno da mundialização da economia. Duas das características das cidades globais já podem ser encontradas em Brasília: de um lado, a forte presença de uma economia de serviços, em detrimento de uma base industrial; de outro, a expansão de um sistema de informações calcado em tecnologias avançadas de comunicação ${ }^{23}$. Brasília, por suas características, pode ser considerada uma cidade pós-industrial, na medida em que nela o setor de serviços é mais importante do que o setor primário e secundário na geração da riqueza. Esta importância estaria assegurada pela função permanente de capital política e pela primazia de atividades de controle e de gestão.

Por outro lado, há no debate atual sobre as metrópoles uma forte tendência a considerar a cidade como uma mercadoria que se vende no mercado mundial em acirrada disputa por investimentos. Brasília vem se inserindo sutilmente nessa dinâmica. Embora não goze da força que cidades como São Paulo e Rio de Janeiro apresentam, Brasília cada vez mais manifesta condições de disputar espaço nesse ranking. Os trunfos de que dispõe para essa empreitada são vários e podem ser sintetizados nos seguintes pontos:

1. mercado de trabalho que demanda perfis socioprofissionais de nível elevado, seja nos padrões educacionais, seja na real competência que daí advém;

2. sede de representações diplomáticas e de organismos internacionais com os quais o Brasil mantém relações, aglutinando pessoas e decisões estratégicas;

3. elevado nível médio de renda, garantindo um mercado consumidor estável, com gostos exclusivos, atraindo produtos sofisticados;

4. sítio favorável à realização de congressos e eventos de porte, em função da infraestrutura hoteleira e aeroportuária que cada vez mais se moderniza para atender clientela de nível internacional;

5. equipamentos culturais e esportivos que colocam a cidade no circuito nacional e internacional dos eventos, dinamizando a indústria do entretenimento;

6. polarização de uma vasta região geoeconômica e formação, junto com Goiânia e Anápolis, de um macro eixo urbano de forte dinamismo e potencial econômico;
22. Em termos prospectivos, estaríamos fazendo um exercício de simulação para as próximas décadas

23. Um bom exemplo é a cidade digital na cidade que já abriga empresas de tecnologia do país e também os datacenters de empresas estatais como a Caixa Econômica Federal e o Banco do Brasil. 
7. por fim, a expansão de um setor "informal" de baixa renda que termina circulando em torno desse núcleo dinâmico, prestando serviços de natureza pessoal aos que participam da esfera mundializada da cidade.

Esse quadro, no qual poderiam ser inseridas muitas outras características, encontra certas limitações justamente na cultura local. As grandes cidades contemporâneas, conforme destaca Sassen (2010: 91), emergem como lugares estratégicos para uma variedade de novos tipos de operações - políticas, econômicas, culturais e subjetivas. Brasília preenche muitas dessas operações até mesmo com a vantagem de não ter concorrentes geograficamente próximos. Entretanto, a política local ainda se ressente de maior contemporaneidade, no sentido de ultrapassar a cultura clientelista que privatiza o aparelho de Estado reproduzindo no seu desenho modernista o que há de mais arcaico nos rincões profundos do Brasil. Além do mais, a cidade ainda guarda características de cidades do mundo subdesenvolvido, com áreas completamente secundárias nas políticas urbanas, acentuando o caráter desigual da sociedade brasileira. É esse descompasso, entre um ambiente físico moderno e um ambiente sociopolítico com sinais de arcaísmo, que precisaria ser ultrapassado.

Isso é assunto para um outro momento...

Abstract: This article seeks to discuss the Brasilia's potential to be part in the worldwide network of cities, because of its peculiar socioeconomic and cultural dynamics. It consolidates here, after 54 years of its inauguration, a city that lives constant processes of change, but it is still attached to the public sector as the sphere that gives its identity. The asymmetry that is observed between its role as a rational city which repels a modernist design and its role as a city that grows in its peripheries in an anarchical way reproducing models of other Brazilian cities, pushes a social structures with huge degrees of inequality and differentiation. Contextualizing it in the contemporary logic of "global" cities, in which the urbane policy is part of a general movement common to other worldwide metropolises, the city seeks to offer some comparative benefits in order to attract investments. In this sense, this article defends that Brasilia today lives an original stage in its evolution, besides its apparent incompatibility between its function as the political capital that in a certain way restricts its potentialities, and its market forces that leads to modify its original nature.

Key Words: Brasilia; bureaucracy; global cities; social inequality; urban planning.

\section{Referências}

BOURDIEU, P. Efeitos do lugar. In Bourdieu, P. (Org.). A miséria do mundo. Petrópolis: Vozes, 1997, p. 159-166.

CAMPOFIORITO, I. Olhares sobre o moderno. Rio de Janeiro: Casa da Palavra, 1990.

CHARLE, Christophe. Les hauts fonctionnaires en France au XIXème siècle. Paris: Gallimard, 1980. 
COLIN, S. Ciam: O movimento moderno na Academia. < http://coisasdaarquitetura. wordpress.com/2010/07/28>. Acessado em 04.02.2014.

DAGORN, R. É. Des villes citadelles aux villes reseau. Revista Sciences Humaines, n. 17, dossier "Villes mondiales. Les nouveaux lieux de pouvoir. Paris: 2009.

DURAND, J. C. Négociation politique et rénovation de l'architecture: Le Courbusier au Brésil. Actes de la Recherche en Sciences Sociales, n. 88, Paris, École des Hautes Études en Sciences Sociales (Ehess), 1991.

DURKHEIM, É. De la division du travail social. 7. ed. Paris: PUF, 1960.

FAORO, R. Os donos do poder: formação do patronato político brasileiro. São Paulo: Globo, 2001.

LACERDA, N. Fragmentação e integração: movimentos de (re) estruturação espacial das metrópoles brasileiras. In: RIBEIRO, A. C. T.; LIMONAD, E. \& GUSMÃO, P. P. Desafios do planejamento: produção da metrópole e questões ambientais. Rio de Janeiro: Letra Capital, 2012, p. 21-42.

LE CORBUSIER (Org.). Carta de Atenas. São Paulo: Hucitec, 1989.

MARQUES, S. Les professions de I'urbanisme au Brésil. 1995. Tese (Doutorado) - École des Hautes Études en Sciences Sociales (Ehess), Paris.

NUNES, B. F. Brasília: a fantasia corporificada. Brasília: Paralelo 15, 2004, p. 39-62.

PESSOA, J. S. de B. Brasília: o tombamento de uma ideia. Escola de Arquitetura e Urbanismo da UFF. <http://www.docomomo.org.br/seminario5.pDistrito Federal/0740pDistrito Federal>. Acessado em 12.07.2013.

RISÉRIO, A. A cidade no Brasil. São Paulo: Editora 34, 2012.

SASSEN, S. Las ciudades en el ilimitado espacio de la red global. Córdoba, ciudad y desarollo: la nueva economia urbana de la ciudad, Municipalidad de Córdoba - Argentina, Ano V, n. 11, Set. 1999.

WEBER, M. Conceito e categoria de cidade. In: WEBER, M. Economia e sociedade: fundamentos da sociologia compreensiva. v. 2. Brasília: Editora Universidade de Brasília, 1999. 
